\title{
A Practical Approach to an Automated Accounting System Development of the Study Results of Historical and Architectural Sites of the Island of Sviyazhsk
}

\author{
Airat G. Sitdikov ${ }^{1,2}$, Eugenia F. Shaykhutdinova ${ }^{1,3}$, Alexei V. Kasimov ${ }^{1}$, Timur R. Azizov ${ }^{1}$, Vlada V. \\ Kugurakova ${ }^{1}$ \\ ${ }^{1}$ Kazan Federal University, ${ }^{2}$ Archaeology Institute, Academy of Sciences of the Republic of Tatarstan, Kazan \\ ${ }^{3}$ Kazan National Research Technical University named after A.N. Tupolev - KAI, Kazan, Russian Federation \\ E-mail: eugen.shaykhutdinova@gmail.com, Contact: +7(987)2369208
}

\section{Received: 21st October 2017 Accepted: 16th November 2017, Published: 31st December 2017}

\begin{abstract}
The 16th century Assumption Cathedral is a true pearl of the architectural ensemble of the island town of Sviyazhsk (Republic of Tatarstan, Russian Federation). Restoration of architectural appearance of the site has been in progress for over a hundred years. This has resulted in an urgent need for systematization and accounting of restoration and research results, as well as monitoring and control of the current condition. An automation system was decided to be established in order to resolve these issues.

The following two major goals are planned to be achieved as part of development of the automation system. On the basis of the established knowledge base, a specialist is going to be able to perform a damage evaluation of the site, determine a complex of protective and salvage activities, and use the accumulated knowledge to carry out scientific research of the site.

The visualization module is going to contain models of the World Heritage Site in 2D and 3D formats with indication of sampling locations.

The monitoring of sites includes surveillance of the variations of temperature and humidity conditions in the course of time and storage of the previously obtained THC data.

The automation system is going to contain all periodical and current observations and research of the object.

Apart from the automation system, a physical sample database is planned to be established. Each sample is going to be assigned a unique number, and the data on each sample contained in the knowledge base is going to include information on the location and date of sampling, as well as the physical storage location of the sample.

Thus, the result of development of the automation system is going to consist in the establishment of a unified information system comprising few modules.
\end{abstract}

Keywords: Archaeology, History, Cultural Heritage Site, Monitoring, Automated System, Unity, 3D, ASP, .NET

\section{Introduction}

The Island of Sviyazhsk is a unique object of historical and cultural heritage $(\mathrm{OHCH})$ of Russia. Natural and geographical location of the island has always attracted the people and has always contributed to an active development of the area. In different periods of time the island was inhabited by Cheremis, Burtases, the Chuvash and Tatars [1]. In the middle of the XVI century after an unsuccessful campaign against Kazan by Tsar Ivan IV it was decided to build a fortress near Kazan [1]. The city was founded and settled at the same time in 1551. According to the chronicles, forest was felled near Uglich and walls, towers, churches and homes were built. Then they were transported on water to The Island of Sviyazhsk [1]. For four centuries Sviyazhsk was spiritual and missionary center. By the beginning of XX century 12 churches and 2 monasteries were operated on the island [1]. After the October Revolution and the Civil War the decline of the city begins. It can be explained by a number of objective reasons. Active measures for the preservation of cultural heritage of Sviyazhsk, started in 2010, made it possible to preserve the unique architectural ensemble of the city, which contributes to the active promotion and development of tourism in Russia. Since the beginning of extensive work on the preservation of the cultural heritage of the island there has been an urgent need to organize and account restoration results and research $[2,3]$, monitoring and control of the current state of Sviyazhsk Heritage.

To resolve these issues, it was decided to set up an automated system (AS) to perform the following tasks:

1. Systematization and unification of research results.

2. The development of accounting systems and storage research results systems.

3. Development of storage systems research samples.

4. The development of storage of archival documentary sources system.

5. Development of an automated system for monitoring the current state.

6. Creating the visualization system of objects heritage in the 2-D and 3-D.

7. Historical reconstruction of heritage objects on archival documentary sources.

The system will include the results of scientific work and reports of the current state of natural sciences, 
biological, climatic, engineering and architectural study of three historical and cultural heritage of Sviyazhsk: Assumption Cathedral, Trinity Church and museumification of "Tatar suburb" excavation.

\section{Methods}

As part of the development of the automated system 2 major tasks will be solved: tracking changes in the state of the object in time (periodic study: engineering condition, identifying the origin of the elements, determining the age of the elements and of the object) and the current status (monitoring of temperature and humidity of the object mode). The objects of study are the elements of wood and stone structures, decorations and others. Features of historical and cultural heritage objects are made up of the research results of these elements. On the basis of established knowledge bank the expert will be able to build a destruction forecast of the object to form fire-rescue works complex and use the knowledge gained for the scientific study of the object.

An automated system will consist of several modules:
1. Visualization.
2. Monitoring.
3. Research.
4. Archive.
5. Database storage of physical samples.

Visualization module should contain models of historical and cultural heritage in 2-D and 3-D display format with sampling locations. In addition to modeling the objects in the current state it is supposed to conduct the historical reconstruction of objects at different times.

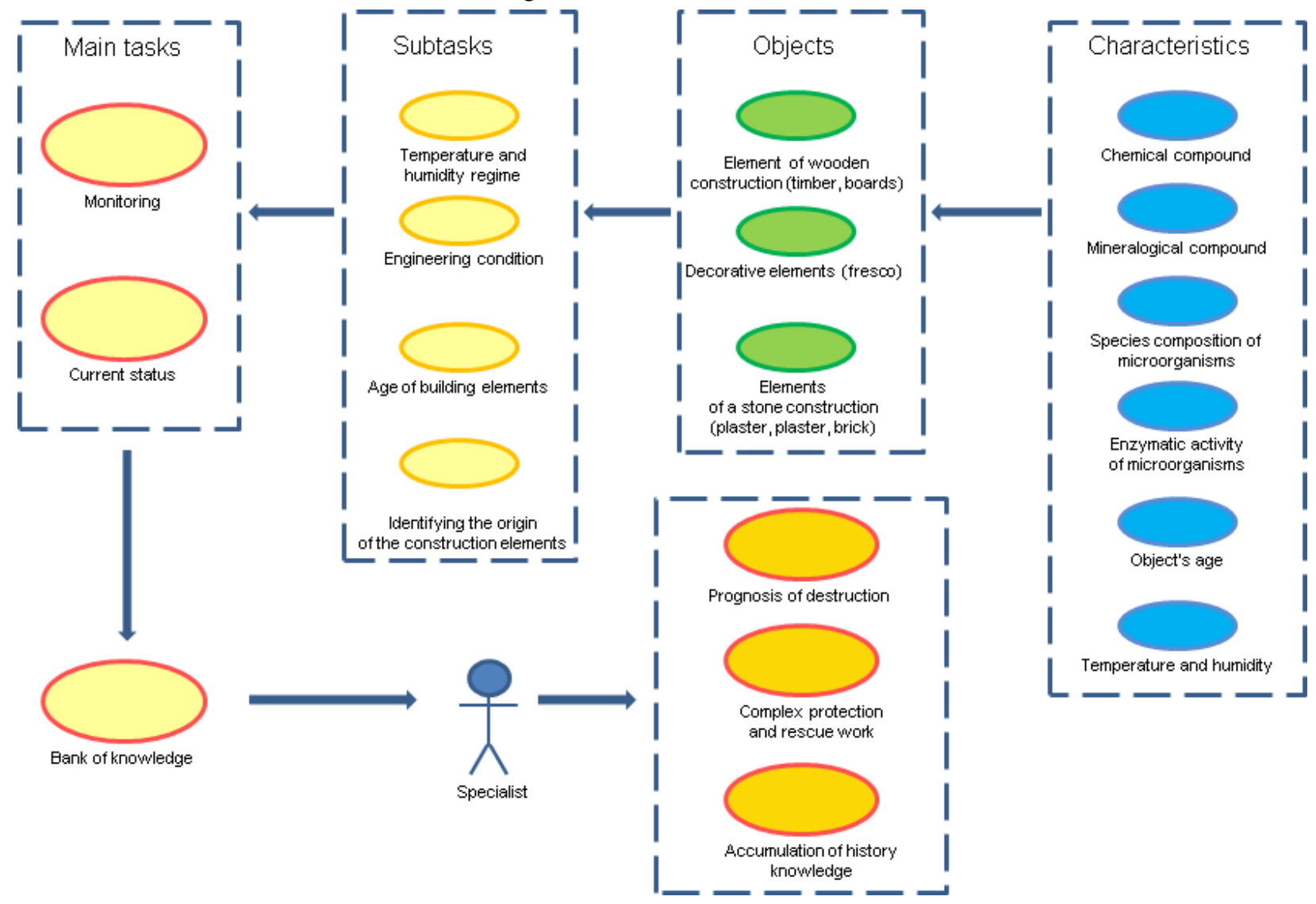

Figure 1. An Automated System Scheme

Monitoring of objects includes observation of changes in temperature and humidity conditions (THC) in time and storage of previous THC data. THC data are supposed to be included in object state register.

It is supposed that different results will be included in automated system, such as the results of microbiology, optical microscopy, scanning electron microscopy, Xray fluorescence analysis, spectral analysis, X-ray phase analysis, technical and technological analysis, dendrochronology, radiocarbon analysis, engineering and architectural analysis. For example, the results of scanning electron microscopy sample number MS021 displayed in tabular form, marked by $2-\mathrm{D}$ and $3-\mathrm{D}$ models, besides a complete report and graphics on this model can be downloaded in pdf format. 

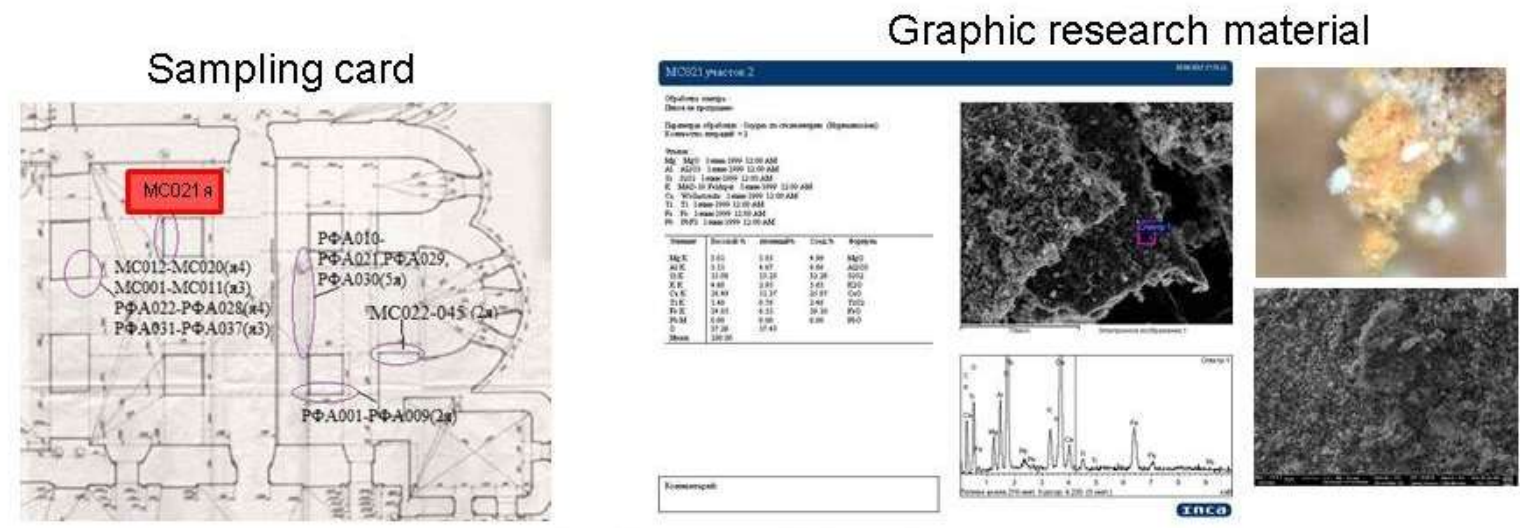

\section{Table of research results}

\begin{tabular}{|c|c|c|c|c|c|c|c|c|}
\hline \multirow{2}{*}{ № } & \multirow{2}{*}{ Location } & \multirow{2}{*}{ Paint Color } & \multicolumn{6}{|c|}{ Chemical composition } \\
\hline & & & $\mathrm{Mg}$ & Al & Si & $\mathrm{Ca}$ & $\mathrm{Fe}$ & $\ldots$ \\
\hline MCoO1 & Wall above the arch in the prayer hall 2,2 tier & Dark red & 0,69 & 0,23 & 1,97 & 1,65 & 71,42 & $\ldots$ \\
\hline MCD02 & Wall above the arch in the prayer hall 2,2 tier & - & 0,18 & 0,38 & 0,13 & 9,02 & 0,61 & $\ldots$ \\
\hline$\cdots$ & $\cdots$ & $\cdots$ & $\cdots$ & $\cdots$ & ... & $\cdots$ & $\cdots$ & $\cdots$ \\
\hline MCO21 & Column 1, the fresco "Varsanofy with horse head" & & 5,76 & 1,48 & 2,29 & 0,58 & 32,35 & \\
\hline
\end{tabular}

Figure 2. Showing Results of Samples Examination by Scanning Electron Microscopy

The archive module will contain all periodic and present monitoring and research facility.

Apart from the automated system it is planned to create a physical sample data base. A unique number will be given to each sample, and information about it in the knowledge base will contain information on the place and date of sampling, as well as the physical storage of the sample. For example, a sample is withdrawn from the MS021 with Varsonof fresco on a column №1 08.06.2015 by scientist-researcher I. Safina, storage Institute of Archaeology. OH. AN RT Khalikov (Restoration and Analysis Division) [4].

Thus, the result of the development of the automated system will be the creation of a unified information system that includes the following modules:

1. TBP monitoring in real time and archive of states;

2. visualization of historical and cultural heritage and its reconstruction;

3. registration and storage of research samples;

4. registration and storage of research results;

5. storage of archival documentary sources.

At the moment, the automated system consists of (1) database, (2) server part (3) of the client in the form of web-pages (for authentication and filling in the directories) and (4) 3D visualization of studies.

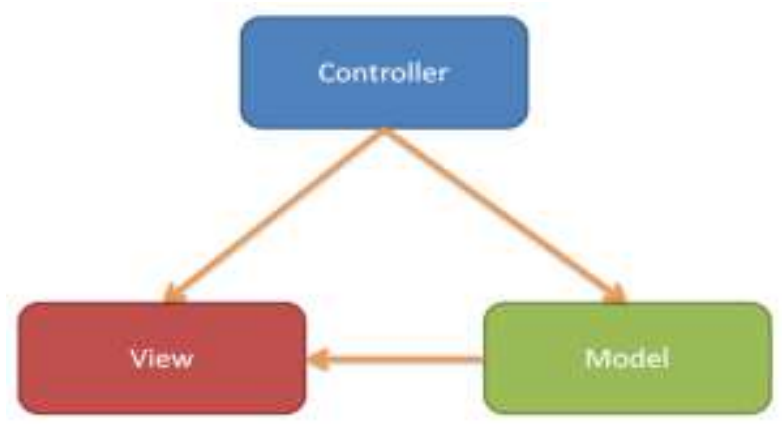

Figure 3. Pattern of Model-View-Controller

For implementation of the server side of the AS ASP.NET technology is used [5]. It allows using the
Model-View-Controller pattern. This pattern implies the division of the system into 3 parts: 
1. Model - data model.

2. View - data representation to the user, the user interface.

3. Controller - part of the system transmitting data from the model to the view and back.

The server part of the developed AS contains the implementation of the model and controller.

To implement the model Microsoft Entity Framework technology is used. It allows the work with the database (DB) through the classes representing the model. Also, this technology makes it easy to make the transition between relational databases. Code first [5] has been used in this AS technique, i.e. firstly, classes representing the model were written, and then the database was generated.

The main essence of the model is the essence of the sample represented in the model class Point. This is the essence of a sample taken from the historical and cultural heritage. It contains information about when and where the sample is taken, the coordinates for its visualization, links to researchers and the studies.

To present research results, the abstract class Analyze has been created. It contains common data to all researches, such as date of study, type of study, links to researchers and to the sample itself. To present the results of a specific study an appropriate heir of the class with the required fields and links is created.

Controllers used in the system are divided into two parts: (1) the standard controllers, which are used for the communication of server and web pages, these controllers are used for logging and editing of data in the database; (2) and webapi - controllers that bind server and $3 \mathrm{D}$ visualization. These controllers transmit and receive json-objects, which store the necessary data.

ASP .net identity technology [6] is used for authorization. Its first advantage is the possibility of a flexible division of roles and giving them different rights for interaction with the system.

View consists of three parts:

1. Web-page

2. $3 \mathrm{D}$ platform to fill the data sample analyzes associated with it, and send the data to the server.

3. 3D-platform for uploading pattern data from the server and their placement on 3Dmodels of historic and cultural heritage objects.

The web-pages are needed to control the tablesreferences, such as researchers' reference or guide of the elements of historic and cultural heritage. The data in these tables are rarely changed during runtime. Moreover, web pages are used to authorize the AS users assigned different levels of access and roles.

\section{Results}

To visualize the data filling the platform has simplified 3D-model of historic and cultural heritage, which was obtained on the basis of drawings [7-9]. In addition, the method of laser scanning helped to obtain the dense cloud of points of two architectural objects: Assumption Cathedral and Trinity Church [10] which will be used in obtaining highly accurate polygonal models.

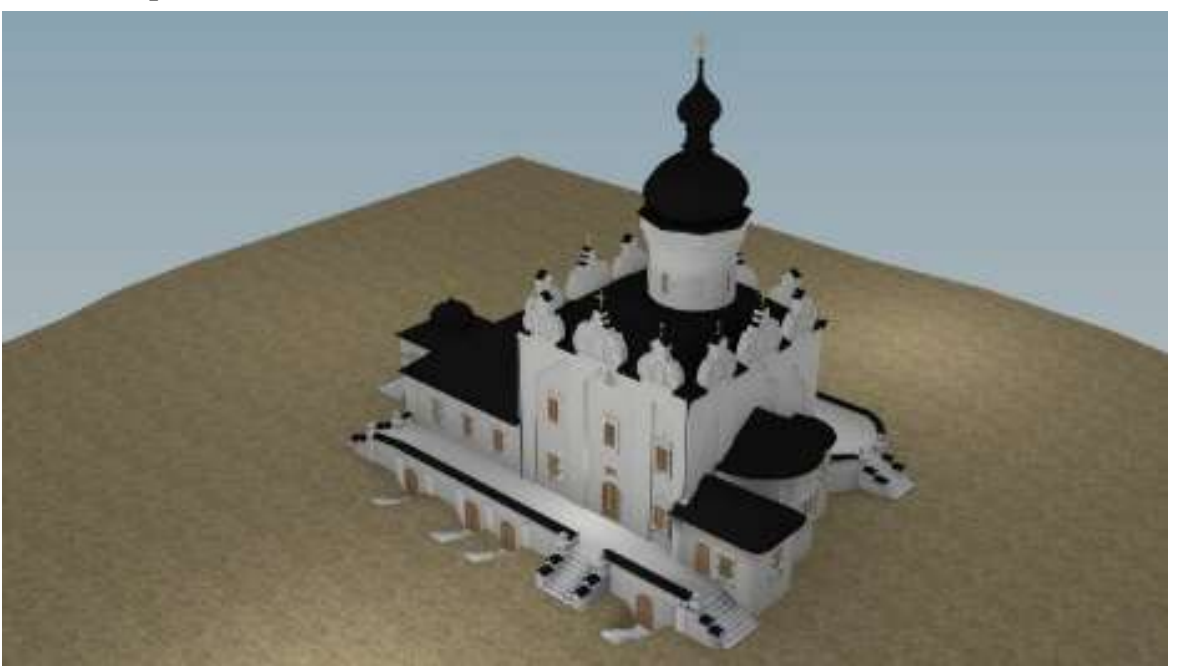

Figure 4. Assumption Cathedral 


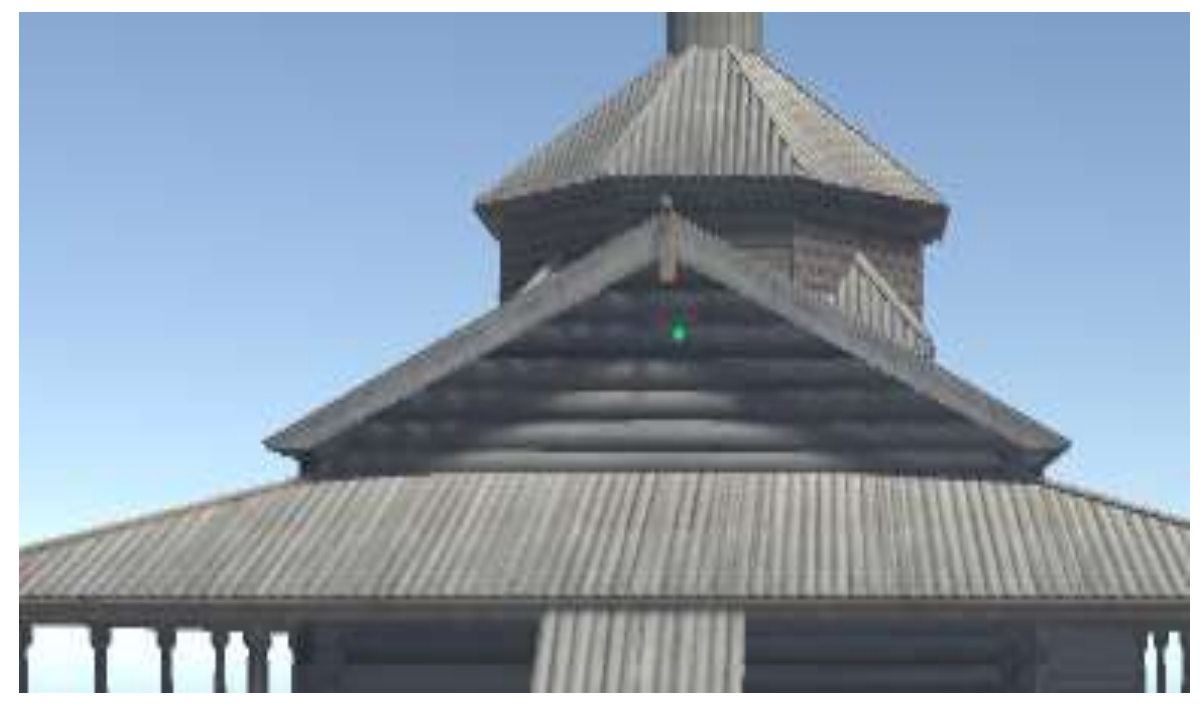

Figure 5. Trinity Church

Mesh collider closely following all the contours of the model is placed on this model. Raycast method of Unity standard set of methods is used to determine the coordinates of the point. It allows you to mark a collision point and physical collider facility. By clicking the left mouse button an object of Point type is created, the panel with a variety of fields is activated, so the data sample and all analyzes are introduced. When you create an example of the Point class, coordinates of the impact points and the collider object representing 3D-model are written. These data are used for subsequent visualization of samples.

For each type of analysis a separate panel is established. It is activated when you press the button with the corresponding name of analysis and deactivated by the addition of the analysis to the point or cancellation. Many of the tests are associated with the reference tables. At startup, all data from the reference tables are downloaded from the server. Applications are available through the drop-down lists.

To communicate with server class Connector is created, which created AddPointInDatabase method that is responsible for sending data on the sample. To communicate with the server WebClient class is used. It contains methods both for sending data to the server and to upload data from the server.

In order to send to the server class Point object is converted into json-line. To serialize an object in json, Newtonsoft json library is used. After that, id parameters of all the tables are added to the Headers. The data is then sent to the server via UploadString method. In response, the server sends the id of the inserted point.

\section{Discussion}

Similarly, analysis data associated with the sample are sent. In order to attribute the study results to the proper sample, the id sample is also sent. In the same way the essence of the database associated with the study are written.

In the platform where the data loading, there is also a model of historical and cultural heritage objects where the visualization of the locations takes place.

Most often, there is a need to receive the AS sample data only on samples with certain parameters, such as sample taken by a certain researcher or the results obtained in a certain period of time, or get a list of research samples, which gave some results. To solve this problem the system of filters is created. For this classes defining a set of parameters have been established. To determine the parameters for filtering the class of PointFilterParametrs is created. It holds the main parameters on which the sample is selected. In this class, there is a reference to an abstract class AbstractAnalyzeFilterParametrs. It defines the basic parameters of the study which the selected sample should possess. To determine the parameters for a particular type of research the heritor of this class is created.

Since it is not always required to take samples for all of the filters it is necessary to check whether we should apply this filter in the request. To do this, in a field of the class that represents the option which means that no filter should be carried out, we need to enter a value for which the system does not concern this filter. For example, if you currently do not need to give samples from specific researchers, in the appropriate field class PointFilterParametrs you should enter null instead of the list. Data filtering is done on the server side by special webapi-controller.

\section{Summary}

Currently modules completing and submitting data to the server and their visualization are implemented. Also the possibility to use some filters for downloaded data is realized. 
The developed automated system for storing the results of research and monitoring of the current state of architectural monuments is ideally suited for systematization and unification of research results, taking into account the visualization of objects in twodimensional and three-dimensional forms, offering historical reconstruction of heritage objects based on archival documentary sources.

It is important to include in the system the results of all previous scientific papers and current reports on the state of the natural sciences, biological, climatic, engineering and architectural studies.

\section{Conclusion}

The given AS solves the problems for the Unification of accounting, storage, fast access to data and intuitive visualization of research results. In this regard, we find it appropriate to launch our AS for all historical and cultural heritage objects where there large-scale and complex research is conducted and there is the necessity to form complex of security rescue works.

\section{Acknowledgement}

The work is performed according to the Russian Government Program of Competitive Growth of Kazan Federal University.

\section{References}

[1] History of restoration of cultural heritage Ostrov City Sviyazhsk. - Kazan: SP Garipova G.G, 2013. - 260 p.

[2] Shaykhutdinova E.F., Kasimov A.V., Sitdikov A.G. Development of an automated system for the recording of results of studying and monitoring of the current condition of historical and architectural sites in the island town of Sviyazhsk // Proceedings of International Congress "Historical, cultural and spiritual heritage of Sviyazhsk", Kazan, Republic of Tatarstan. 15-16 July 2015. Pp. 254-258.

[3] Shaykhutdinova E., Kasimov A., Sitdikov A. Preliminary results of the development of a unified system for the research and monitoring of the current condition of the 17th century Assumption Cathedral in the island town of Sviyazhsk (Tatarstan, Russia) // Proceedings of the 5th International Conference on Heritage and Sustainable Development. Volume 2. Lisbon, Portugal, 12-15 July, 2016. Pp. 14811488.

[4] Khramchenkova R.K., Batalin G.A., Gareyev B.I., Kaplan P.Y., Kosushkin V.F., Sitdikov A.G. The study of the paint layer of frescoes // Assumption Cathedral. Study and preservation. Kazan: OOO Glavdizayn, 2016. Pp. 126-136.

[5] Pranav Rastogi, Rick Anderson, Tom Dykstra and Jon Galloway. Introduction to ASP.NET Identity. October 17, 2013.

[6] MSDN. Technology Code First to create a database.

[7] Bugrov D.G., Gainullin I.I., Kasimov A.V., Sitdikov A.G., Starovoytov A.V., Usmanov B.M, Chernova I.Y. An integrated approach to the collection of information for visualization of historic and cultural heritage of The island of Sviyazhsk // Virtual Archaeology (the effectiveness of methods): Proceedings of the Second International Conference, on 13 June 2015, the State Hermitage Museum / The State Hermitage Museum. SPb.: Izdvo State. Hermitage, S. 2015. 103-112.

[8] Gainullin I.I., A.V. Kasimov, Usmanov B.M. Three-dimensional modeling of objects of cultural heritage of the historical settlement of Sviyazhsk // The Second International Conference "Archaeology and Geoinformatics", 20-22 May 2015, the Institute of Archaeology RAS. Report.

[9] Kasimov A.V., Sitdikov A.G., Shaykhutdinova E.F., Usmanov B.M. Visualization of the Assumption Cathedral // Assumption Cathedral. Study and preservation. Kazan: OOO Glavdizayn, 2016. Pp. 58-75.

[10] Usmanov B.M., Zagretdinov R.V., A.V. Starovoytov. Creating of precision models of unique architectural objects of Bolgar and Sviyazhsk // IV International scientific and practical conference. Actual issues of geodesy and geo-information systems within the framework of the Tatarstan petrochemical forum. September 23, 2015, Kazan. 